\title{
AVALIAÇÃO DO PROCESSO DE REABILITAÇÃO DE UM TRECHO DE FLORESTA CILIAR NA BACIA DO RIO ITAPEMIRIM-ES ${ }^{1}$
}

\author{
Malcon do Prado Costa ${ }^{2}$, Mauro Eloi Nappo ${ }^{3}$, Fabiana Ramos Dias Caçador ${ }^{4}$ e Herbertom Henrique \\ Dimas de Barros ${ }^{4}$
}

RESUMO - Este estudo foi realizado em uma área de floresta ciliar em processo de recuperação mediante reabilitação. A área de estudo está localizada na sub-bacia hidrográfica do rio Itapemirim, no Município de Alegre, ES, Brasil. A ocupação e uso do solo antes da revegetação eram de pastagem com Brachiaria sp. A revegetação da área foi feita em 1997, com espécies autóctones e alóctones arbóreas, em arranjo de distribuição aleatório, em uma área de 1,2 ha. Para a realização dos estudos foram feitos inventários florestais nos períodos de 2004/2005 e 2005/2006, sendo medidos os indivíduos de hábito arbustivo e arbóreo com circunferência à altura do peito (CAP) $\geq 5 \mathrm{~cm}$ e suas alturas totais. As espécies encontradas na área foram identificadas e classificadas de acordo com seus grupos ecológicos, síndromes de dispersão e presença silvestre, sendo calculados os parâmetros florísticos, a estrutura vertical e a dinâmica estrutural desse povoamento. O objetivo do trabalho foi avaliar o desenvolvimento do povoamento implantado para subsidiar práticas silviculturais quanto à seleção e implantação de espécies para revegetação de áreas de floresta ciliar degradadas, em condições semelhantes. Os resultados demonstraram que foi implantado um povoamento florestal com grande diversidade de espécies e a estratificação em classes de altura foi à semelhança de povoamentos heterogêneos naturais. As espécies identificadas como edificadoras da revegetação da área estudada foram: Anadenanthera colubrina, Caesalpinia leyostachia, Acacia auriculiformis, Acacia mangium, Handroanthus serratifolius, Inga edulis, Joannesia princeps, Pterogyne nitens, Enterelobium contortisiliquum, Tabernaemontana hystrix e Anthocephalus indicus. A distribuição em classes de tamanho da comunidade implantada ocorre em forma de "J" reverso, havendo a predominância de indivíduos pioneiros em todas as classes de CAP. A dinâmica da estrutura horizontal apontou que, para o sucesso, continuidade e desenvolvimento da recuperação da área, seja monitorada a regeneração natural em relação à sua presença e à eficiência dos fatores bióticos e abióticos que nela interferem. A não observância de indivíduos arbustivos e arbóreos regenerados naturalmente, na classe de inclusão do estudo, indica a fragilidade inicial da área rumo à sustentabilidade do sistema.

Palavras-chave: Recuperação de áreas degradadas e Florestas ciliares.

\section{EVALUATION OF THE PROCESS OF REABILITATION OF A STRETCH OF RIPARIAN FOREST IN ITAPEMIRIM RIVER WATERSHED - ES}

\begin{abstract}
The study was realized in an area of riparian forest in process by means of rehabilitation. The study area is located in Rio Itapemirim, in Alegre city, Brazil. The occupation and use of the soil before the recovery were of pasture with Brachiaria sp. The recovery of this area was in 1997, with autochthonous and allochthonous species, in casually distribution arrangement, in an area of 1,2 ha. For this studies was realized forest inventories in the periods of 2004/2005 and 2005/2006, being measured the arboreal individuals with circumference at breast height $(\mathrm{CBH})$ and total heights. The species found in the area were identified and classified in this ecological groups, dispersion syndromes and wild presence, it forms calculated the floristic parameters, the vertical structure and the structural dynamics of this plantation. The objective of this work went evaluate the development of the plantation implanted to subsidize practical silviculture with relationship to the selection and plantation of species for the revegetation of degraded areas of riparian forest, in similar conditions. The results of the studies demonstrated that a forest plantation was implanted with great diversity of species and the bedding in height classes it went to the likeness of natural heterogeneous. The species identified as builders of the plantation of the studied area were: Anadenanthera colubrina, Caesalpinia
\end{abstract}

\footnotetext{
${ }^{1}$ Recebido em 09.10.2007 e aceito para publicação em 02.03.2010.

${ }^{2}$ Universidade Federal de Santa Maria, UFSM, Brasil. E-mail: <malconfloresta@gmail.com>.

${ }^{3}$ Universidade de Brasília, UnB, Brasil. E-mail: >mauronappo@yahoo.com.br>.

${ }^{4}$ Universidade Federal do Espírito Santo, UFES, Brasil. E-mail: <frdcacador@yahoo.com.br>, <miracidiobr@yahoo.com.br>.
} 
leyostachia, Acacia auriculiformis, Acacia mangium, Handroanthus serratifolius, Inga edulis, Joannesia princeps, Pterogyne nitens, Enterelobium contortisiliquum, Tabernaemontana hystrix, and Anthocephalus indicus. The implanted community's distribution diametric happens in reverse J shape having the pioneer individuals' predominance in all the classes of $\mathrm{CBH}$. The dynamics of the horizontal structure points that for the success, continuity and development of the recovery of the area, the natural regeneration be monitored in relation to its presence and efficiency of the biotic factors and abiotic those interfere in the same. The not tree individuals observance in natural regeneration, in the class of inclusion of the study, indicate the initial fragility of the area heading for sustentabilidade of the system.

Keyworks: Recovery of degraded areas e Riparian forests.

\section{INTRODUÇÃO}

Uma área degradada pode ser recuperada tendo em vista sua destinação para diversos usos possíveis. Todavia, o termo recuperação não se aplica indistintamente a todos os usos possíveis (NOFFS et al., 2000). O processo de recuperação de um ecossistema natural, perturbado pela ação antrópica, pode ser feito mediante: restauração que é realizada através de práticas ecológicas e silviculturais do ecossistema, onde são recuperadas a forma e função original dos ambientes antes de sua degradação, restabelecendo-se sua composição e diversidade de espécies, estrutura trófica, fisionomia e dinâmica original; reabilitação é aquela em que uma nova função e, ou, forma biológica diferentes da original são aceitáveis, desde que seja estabelecida uma nova condição biológica estável em conformidade com os valores ambientais, estéticos e sociais da circunvizinhança; e redefinição é a transformação do ambiente degradado a uma nova forma e função não biológica (MAJER, 1989; BRASIL, 1990; ENGEL e PARROTA, 2003). A reabilitação em muitos casos é uma etapa fundamental para se chegar à restauração.

As florestas ciliares ocorrem em gradientes de transição entre corpos d'água e terra firme, sendo facilmente influenciadas pela topografia e flutuações climáticas. Essa heterogeneidade ambiental é certamente a principal geradora de riqueza florística, pois determina uma condição ecotonal para faixa ciliar, que é ocupada por um mosaico de tipos vegetacionais ou unidades fitogeográficas, cada qual com suas similaridades florísticas (RODRIGUES e NAVE, 2000). As florestas ciliares apresentam interfaces com vários outros tipos de vegetação, servindo como áreas de escape de variadas espécies durante flutuações ambientais (OLIVEIRA FILHO e RATTER, 2000). Essas informações revelam a importância da recuperação de áreas ripárias degradadas por atividades de origem antrópica, mesmo por que as florestas ciliares ocorrem em áreas definidas pela legislação brasileira como de preservação permanente, devendo, por isso, ser preservadas e recuperadas as que foram degradadas.

Lourenzo (1991) e Nappo et al. (2004) consideraram que a revegetação de áreas degradadas, como as para recuperação de florestas ciliares, devem implicar não apenas plantio de espécies vegetais, mas também seleção adequada das espécies e das técnicas de manejo que acelerem e restabeleçam os processos de sucessão natural, caminho mais apropriado para a formação e restabelecimento da função e, ou, forma da vegetação.

Reis et al. (2003) e Bechara et al. (2007) defenderam que os projetos de recuperação devem priorizar a revitalização de processos criadores de condições específicas para a estabilização de espécies autóctones no ambiente perturbado, a partir da criação de núcleos de regeneração e não apenas o plantio de espécies. Os conhecimentos adquiridos sobre a recuperação de florestas ciliares degradadas apontam que a escolha entre técnicas de revegetação e, ou, processos nucleadores como parte essencial do processo irá depender do nível de estabilidade e resiliência do ecossistema de estudo (banco de propágulos do solo, conectividade com outros fragmentos, competição com gramíneas invasoras etc.), bem como dos objetivos futuros da área a ser recuperada.

A realização de estudos básicos e contínuos, sobre o desenvolvimento de espécies utilizadas em reflorestamentos de áreas degradadas, são ferramentas importantes para orientar a artificialização da composição florística e fitossociológica em implantações de povoamentos mistos para a recuperação de ambientes. Esses estudos podem produzir relevantes informações quanto à seleção de espécies (sobrevivência, estabelecimento e desenvolvimento), espaçamento e arranjo de plantio e para a elaboração, monitoramento e avaliação de programas de recuperação de áreas degradadas (NAPPO et al., 2004). 
O objetivo deste trabalho foi avaliar o desenvolvimento de um plantio heterogêneo com espécies arbóreas, autóctones e alóctones, em áreas de floresta ciliar. A partir da análise da composição florística, da classificação das espécies em grupos ecológicos, das síndromes de dispersão, da presença silvestre e da caracterização das estruturas de tamanhos e da dinâmica da estrutura horizontal, inferir sobre a sustentabilidade do sistema.

\section{MATERIAL E MÉTODOS}

O levantamento foi realizado à margem direita de um córrego de divisa da Fazenda Barra de Santa Angélica, localizada no Distrito de Rive, Município de Alegre, Sul do Estado do Espírito Santo. A fazenda está situada no rio Alegre, afluente da bacia do Itapemirim, entre as latitudes $20^{\circ} 46^{\prime}$ e $20^{\circ} 55^{\prime}$ sul e longitudes $41^{\circ} 28^{\prime} \mathrm{e}$ $41^{\circ} 37^{\prime}$ oeste de Greewinch.

Segundo a classificação de Köppen, o clima da região é do tipo Cwa, caracterizado como verões chuvosos e invernos secos (PEZZOPANE et al., 2006). A temperatura anual média de $23,1^{\circ} \mathrm{C}$ sendo a média das máximas do mês mais quente entre 30,7 e $34^{\circ} \mathrm{C}$ e das mínimas do mês mais frio entre 11,8 e $18^{\circ} \mathrm{C}$. A precipitação média anual em torno de $1.200 \mathrm{~mm}$ (dados referentes ao período de 1976 até 2005), com menor volume mensal entre maio e setembro e com maior intensidade de chuva de outubro e abril, com os períodos chuvoso e seco, respectivamente, em dezembro e junho (INCAPER, 2006).

Em geral, o relevo é bastante acidentado, com reduzidas áreas planas intercaladas, onde se encontram basicamente culturas de subsistência (1,50\%), café (10,02\%) e grande predomínio de pastagens $(67,87 \%)$, além de remanescentes florestais nativos (14,31\%), localizados principalmente nos topos de morros, entre outros usos (NASCIMENTO et al., 2005). Em termos de altitude, a área apresenta uma cota mínima de 160 m e uma cota máxima de 250 m, e o relevo varia de inclinado (não inundável) a plano (inundável).

A vegetação original da região é caracterizada como Floresta Estacional Semidecidual, de acordo o sistema de classificação da vegetação brasileira do IBGE (VELOSO et al., 1991), sendo a área de estudo uma floresta ciliar com influência fluvial sazonal (RODRIGUES, 2000). Os fragmentos de vegetação natural situados na região de entorno da área estudada são poucos, de pequeno tamanho e muito antropizados.

\subsection{Características da área de estudo}

Na área de estudo, o uso do solo era destinado a práticas depecuária, comnível demanejoB(pouco tecnificado), sobre pastagem plantada com Brachiaria sp. Em 1996, foi elaborado um projeto técnico visando à implantação de um povoamento misto com espécies arbóreas diversas (autóctones e alóctones), com arranjo em quincôncio, como parte do processo de recuperação da floresta ciliar.

O plantio foi realizado em 1997, em espaçamento de 3 x 3 m (1.111 mudas/ha). A distribuição das espécies não seguiu o padrão de distribuição projetado, sendo substituído o arranjo em quincôncio por um arranjo com distribuição aleatória. As espécies utilizadas no plantio, em sua maioria, foram diferentes das indicadas no projeto inicial, o que justifica os levantamentos florísticos e estrutrurais realizados. Consequentemente, a proporção de número de indivíduos, de cada espécies e de cada grupo ecológico também foi diferente do planejado inicialmente. O trecho objeto deste estudo corresponde a 1,2 ha, sendo escolhido devido à sua heterogeneidade, no que diz respeito à declividade do terreno e ao regime de inundação. Como base cartográfica foi confeccionado um mapa planimétrico na escala 1:1.500 (Figura 1).

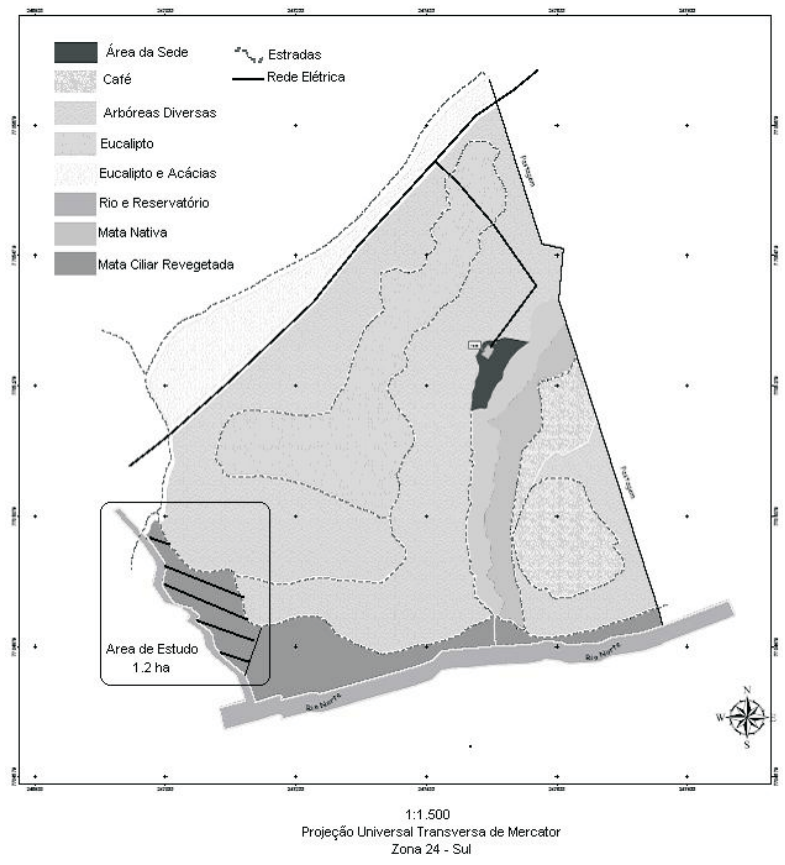

Figura 1 - Mapa Planimétrico da Fazenda Barra de Santa Angélica, em Alegre, ES.

Figure 1-Planimetric map of the Farm Bar of Angélica Saint, in Alegre, ES.

Revista Árvore, Viçosa-MG, v.34, n.5, p.835-851, 2010 


\subsection{Obtenção dos dados}

O povoamento florestal em estudo foi avaliado através de inventários florestais mediante o censo, realizados em 2004/2005 e 2005/2006, em que foram identificados e medidos todos os indivíduos de porte arbustivo e arbóreo com circunferência à altura do peito (CAP) igual ou superior a $5 \mathrm{~cm}$ e estimada a altura total com o auxílio de uma baliza graduada.

Para a identificação das espécies foram coletados materiais botânicos para comparação em herbário, feitas análises dendrológicas dos indivíduos e consulta a especialistas. As espécies foram classificadas nas famílias reconhecidas pelo sistema do Angiosperma Phylogeny Group II (APG II, 2003). Os dados do inventário foram organizados em planilhas eletrônicas, e os parâmetros da composição florística e estrutura horizontal foram calculados com a utilização da planilha eletrônica Excel do Microsoft Windows.

As espécies foram classificadas por grupos ecológicos de acordo com a sua categoria sucessional, como o sugerido por Gandolfi et al. (1995), aplicandose os conceitos de Budowski (1965), Denslow (1980), Martinez-Ramos (1985) e Swaine e Whitmore (1988), o auxílio de referências bibliográficas (KAGEYAMA et al., 1992; OLIVEIRA-FILHO, 1994; ROLIM et al., 1999; GANDOLFI, 2000; MARTINS e RODRIGUES, 2002; JESUS, 2002; PEREIRA, 2006), o trabalho de consultores especializados e observações feitas no campo. As quatro categorias sucessionais correspondem à tolerância das espécies à sombra e foram as seguintes: pioneira, secundária inicial, secundária tardia e não classificada. As espécies secundárias tardias foram consideradas mais tolerantes à sombra e de categoria sucessional mais avançada, enquanto as espécies intolerantes à sombra foram incluídas na classificação de pioneiras. Foram classificadas as síndromes de dispersão das espécies de acordo com van der Pijl (1982), como: anemocóricas, aquelas cujas sementes são disseminadas pelo vento; zoocóricas, espécies que apresentam características indicativas que a dispersão de suas sementes ou propágulos é realizada por animais; e autocóricas, aquelas espécies que dispersam suas sementes pela gravidade ou por deiscência explosiva.

Para definição da Presença Silvestre das espécies foram realizadas pesquisas regionais e bibliográficas a partir dos trabalhos de Rizzini (1979), Lorenzi (2000, 2002 e 2003) e Carvalho (1994), tendo sido classificadas em autóctones as espécies originárias que ocorrem naturalmente do mesmo ecossistema onde habitam (GOODLAND, 1975); e alóctones as espécies que se encontram fora do seu ecossistema natural e possuem sua distribuição natural em biomas de outras regiões fitogeográficas (LEMAIRE e LEMAIRE, 1992).

\subsection{Análise dos dados}

Os parâmetros analisados foram: Composição Florística; Diversidade de Espécies; Equabilidade; Densidade; Dominância; Estrutura de Tamanhos; e Espécies de Baixa Densidade. Para avaliar a dinâmica foram calculados o incremento periódico anual e o crescimento bruto e as taxas Anuais médias; de rotatividade; e de mudança líquida no período. Esses parâmetros foram quantificados por espécie. Dessa forma, foi avaliado qualitativa e quantitativamente o comportamento das espécies no intervalo de tempo decorrido entre os dois inventários.

\subsection{Dinâmica da composição florística}

A diversidade florística artificializada foi avaliada utilizando o índice de diversidade de Shannon calculado pela expressão de Poole (1974) e o índice de equabilidade de Pielou (1969), calculado conforme Margalef (1989). A diversidade florística dos levantamentos foi comparada entre si, mediante o teste $\boldsymbol{t}$, descrito por Magurran (1988).

Foram caracterizadas como espécies de baixa densidade as que apresentaram um indivíduo no levantamento, quantificadas em porcentagem do número total de espécies.

\subsection{Dinâmica das estruturas horizontal, vertical e de classes de circunferência}

A estrutura fitossociológica horizontal foi quantificada mediante os parâmetros de densidade e dominância, em suas formas absoluta e relativa. Esses parâmetros dizem respeito à ocupação espacial das espécies arbóreas na comunidade, permitindo quantificar a participação de cada uma na cobertura vegetal e de uma em relação à outra (MUELLER-DOMBOIS e ELLENBERG, 1974; SCOLFORO e MELLO, 1997; DURIGAN, 2003).

A densidade refere-se ao número de indivíduos de determinada espécie na comunidade vegetal amostrada por unidade de área. A dominância expressa 
a proporção de tamanho, biomassa, volume ou de cobertura de cada espécie, em relação ao espaço ou volume ocupado pela comunidade (MARTINS, 1993). Uma das formas mais comuns de calcular a dominância para comunidades arbóreas é a razão entre a área basal total por espécie e a área amostrada. A soma dos valores relativos da densidade (número de indivíduos) e dominância (área basal) por espécie permite obter o Índice de Valor de Cobertura (IVC).

Para analisar a estrutura vertical da floresta foi utilizada a Posição Sociológica das espécies no povoamento, e a partir da metodologia de Sousa (1999) o dossel da floresta foi subdividido em estratos superior, médio e inferior, de acordo com o desviopadrão das alturas.

A dinâmica do povoamento florestal implantado foi realizada mediante os dois inventários realizados na área, o primeiro em 2004/2005 e o segundo em 2005/ 2006, a partir da comparação dos parâmetros fitossociológicos da estrutura horizontal artificializada e o cálculo de parâmetros da dinâmica.

Os cálculos do Incremento Periódico Anual (IPA) em diâmetro, por espécie, no período de monitoramento e do Crescimento Bruto (CB), em área basal, foram realizados conforme Ferreira (1997) e Husch et al. (1993), respectivamente.

$$
\begin{aligned}
& I P A_{i j}=\sum_{k=1}^{N}\left(D_{k, j+1}-D_{k, j}\right) \cdot\left(\frac{10}{N \cdot P}\right) \\
& C B=G f-G i
\end{aligned}
$$

Em que: IPA $_{\mathrm{i}}=$ incremento periódico anual, em diâmetro (mm/ano); $\mathrm{D}$ = diâmetro de tronco à altura do peito; $\mathrm{k}$ = espécie; $\mathrm{j}$ = ocasiões de medição; $\mathrm{N}=$ número de indivíduos amostrados, por espécie; e $\mathrm{P}$ = intervalo de monitoramento (anos). $\mathrm{CB}=$ crescimento bruto, excluindo o ingresso; Gf = área basal $\left(\mathrm{m}^{2} / \mathrm{ha}\right)$ dos indivíduos vivos no final do período; e Gi = área basal ( $\mathrm{m}^{2} / \mathrm{ha}$ ) inicial dos indivíduos vivos.

O recrutamento é o processo pelos quais novos indivíduos entram na nova etapa de medição, e a mortalidade é o número de indivíduos que morreram durante esse espaço de tempo, enquanto a perda e ganho são os equivalentes em área basal. Essas informações são de extrema importância para que as florestas naturais possam ser utilizadas em base sustentável (AZEVEDO et al., 1995). As mudanças no tamanho populacional por intervalo de tempo foram obtidas pelas taxas anuais médias, para as espécies com abundância $\geq 10$ indivíduos no povoamento e para toda a comunidade arbórea, de acordo com Sheil et al. (1995, 2000), com base nas populações iniciais, para mortalidade (M) e perda (P) e nas populações finais, para recrutamento (R) e ganho (G), e, dessa forma, calculadas as taxas anuais médias, obtidas por meio das seguintes expressões exponenciais:

$$
\begin{aligned}
& M=\left\{1-\left[\frac{\left(N_{o}-N_{m}\right)}{N_{o}}\right]^{t^{-1}}\right\} x 100 \\
& R=\left[1-\left(1-\frac{N_{r}}{N_{t}}\right)^{t^{-1}}\right] \times 100 \\
& P=\left\{1-\left[\frac{\left(A B_{o}-A B_{m}-A B d\right)}{A B_{o}}\right]^{t^{-1}}\right\} x 100 \\
& G=\left\{1-\left[1-\frac{\left(A B_{r}+A B_{g}\right)}{A B_{t}}\right]^{t^{-1}}\right\} x 100
\end{aligned}
$$

em que $t=$ tempo decorrido entre os inventários; $N_{o}=$ número de indivíduos inicial; $N_{t}=$ número de indivíduos final; $N_{m}$ = número de indivíduos mortos; $N_{r}=$ número de indivíduos recrutados; $A B_{o}=$ áreas basal inicial dos indivíduos; $A B_{t}=$ áreas basal final dos indivíduos; $A B_{m}=$ área basal dos indivíduos mortos; $A B_{r}=$ área basal dos indivíduos recrutados; $A B_{d}=$ decremento em área basal; e $A B_{g}=$ incremento em área basal.

As taxas de rotatividade (turnover) expressam a dinâmica global do povoamento e foram obtidas a partir das médias das taxas, de mortalidade e recrutamento, para número de árvores $\left(\mathrm{T}_{\mathrm{N}}\right)$ e de perda e ganho, para área basal $\left(\mathrm{T}_{\mathrm{AB}}\right.$ ) (OLIVEIRA-FILHO et al., 1997; WERNECK e FRANCESCHINELLI, 2004; MACHADO, 2005).

$$
T_{N}=\frac{(M+R)}{2} \quad T_{A B}=\frac{(P+G)}{2}
$$

em que $\mathrm{T}_{\mathrm{N}}=$ taxa de rotatividade em número de indivíduos; $\mathrm{e}_{\mathrm{AB}}$ = taxa de rotatividade em área basal. 
Conforme Korning e Balslev (1994), foram obtidas as taxas de mudança líquida no período, tanto para número de árvores quanto para área basal, obtidas a partir das seguintes equações:

$$
\begin{aligned}
C h_{N} & =\left[\left(\frac{N_{t}}{N_{o}}\right)^{t^{-t}}-1\right] \times 100 \\
C h_{A B} & =\left[\left(\frac{A B_{t}}{A B_{o}}\right)^{t^{-1}}-1\right] \times 100
\end{aligned}
$$

em que $C h_{N}=$ taxa de mudança líquida no período, em número de indivíduos; e $\mathrm{T}_{\mathrm{AB}}=$ taxa de mudança líquida no período, em área basal.

Foram elaborados histogramas de frequência para a CAP, e os intervalos de classe foram referenciados de acordo com os dados do primeiro levantamento (2004/2005), pela fórmula: A/K, em que A representa a amplitude dos valores de circunferência e K o número de intervalos de classes, definido pelo algoritmo de Sturges $(1+3,3 \log n)$, em que n é o número total de indivíduos amostrados. Foi utilizado o teste de Kolmogorov-Smirnov (ZAR, 1999) para comparar as estruturas da comunidade florestal implantada entre os anos de acompanhamento. Analisou-se a significância das modificações nas frequências anuais pela aderência das diferentes distribuições entre os períodos de 2004/2005 e 2005/2006.

\section{RESULTADOS E DISCUSSÕES}

\subsection{Dinâmica da composição florística}

No primeiro inventário, em 2004/2005, foram medidos e identificados na área em estudo 800 indivíduos arbustivos e arbóreos com CAP igual ou superior a $5 \mathrm{~cm}$, pertencentes a 31 famílias e 93 espécies, sendo 38 pioneiras, 30 secundárias iniciais, 17 secundárias tardias e 8 não classificadas. No segundo inventário, em 2005/2006 foram medidos e identificados na mesma área 798 indivíduos arbóreos na classe de inclusão, pertencentes a 31 famílias e 96 espécies, sendo 39 pioneiras, 30 secundárias iniciais, 18 secundárias tardias e 9 não classificadas.

Todas as espécies que ocorreram no primeiro inventário também ocorreram no segundo, e este, por sua vez, apresentou, em relação ao primeiro, um ingresso de três espécies, ambas originadas do plantio.
As famílias com maior número de espécies foram: Fabaceae, com 33, sendo 13 da subfamília Mimosoideae, 10 da subfamília Faboideae, 9 da subfamília Caesalpinioideae e 1 da subfamília Cercideae; Bignoniaceae, com 10; 6 espécies para Malvaceae; e 5 espécies tanto em Anarcadiaceae quanto para Meliaceae e Myrtaceae.

Em relação à síndrome de dispersão, para o primeiro inventário o povoamento apresenta 32 espécies anemocóricas, 25 autocóricas e 36 zoocóricas; e para o segundo inventário, 33 anemocóricas, 25 autocóricas e 38 zoocóricas.

Quanto à presença silvestre, de acordo com os gráficos da Figura 2, foram registradas 31 espécies alóctones com 182 indivíduos e 62 espécies autóctones com 618 indivíduos, para o primeiro inventário; e 33 espécies alóctones com 183 indivíduos e 63 espécies autóctones com 615 indivíduos, para o segundo inventário. Esse aspecto permite considerar que o processo de recuperação da área de floresta ciliar estudada está se dando mediante a reabilitação, uma vez que não houve a preocupação com o retorno da forma da vegetação próxima da original.

O povoamento estudado apresentou índices de diversidade artificializada quando da revegetação da área de $\mathrm{H}^{\prime}{ }_{2004 / 2005}=3,9348$ e $\mathrm{H}_{2005 / 2006}=3,9550$, caracterizando elevada diversidade, do ponto de vista quantitativo, para áreas revegetadas. A maioria das espécies amostradas são originárias da artificialização propiciada quando da revegetação, o que permite considerar que entre os períodos estudados na área não houve alteração significativa de diversidade de espécies, corroborando o teste $t$ entre os índices. Esse fato é devido ao pequeno desenvolvimento da regeneração natural na área, refletindo a fragilidade do sistema quanto à implementação dos processos de sucessão. Na Tabela 1 representa os índices de diversidade florística e de equabilidade e o número de indivíduos e de espécies presentes nos dois inventários (2004/2005 e 2005/2006).

A quantidade de espécies de baixa densidade foi alta, com porcentagens de 21,51\% e 22,92\%, respectivamente, para os inventários (2004/2005 e 2005/2006), o que explica os elevados índices de Shannon encontrados em áreas em processos de recuperação. O uso de espécies de 

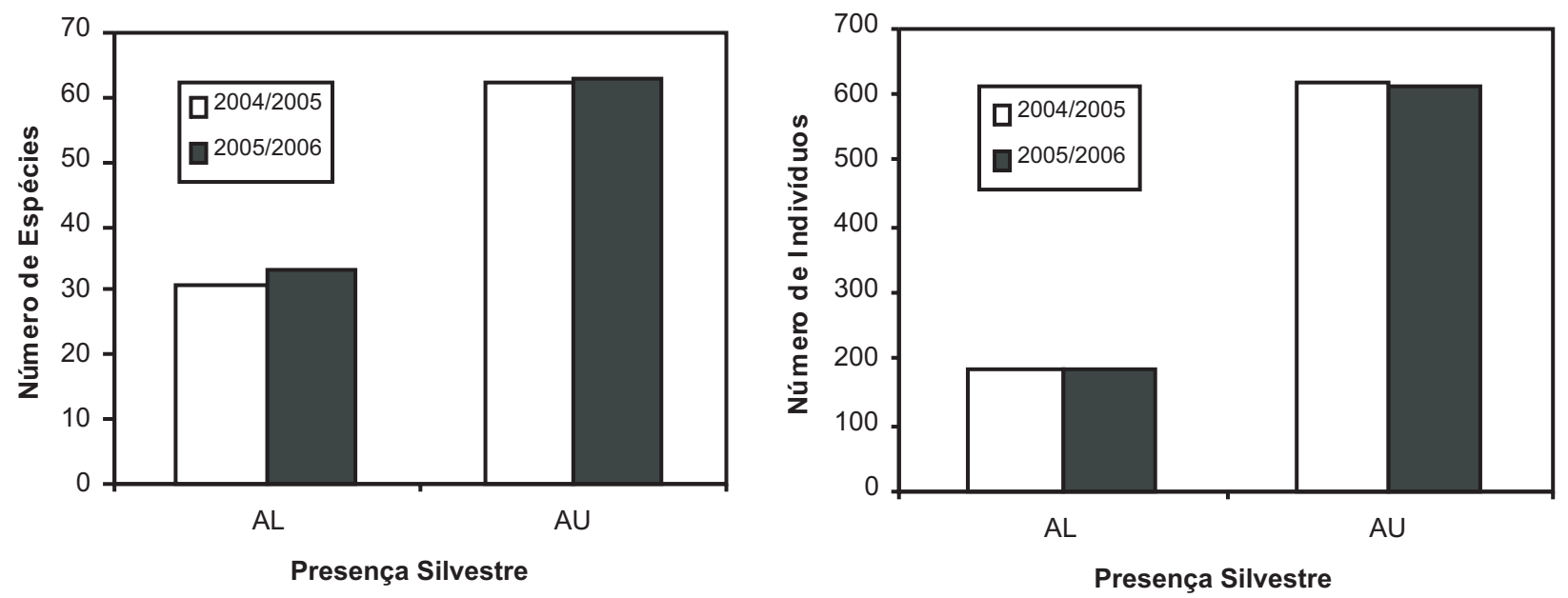

Figura 2 - a) Número de espécies por presença silvestre, observado em 2004/2005 e 2005/2006, na Fazenda Barra de Santa Angélica, em Alegre, ES. b) Número de indivíduos por presença silvestre, observado em 2004/2005 e 2005/2006, na Fazenda Barra de Santa Angélica, em Alegre, ES.

Figure 2 - a) Number of species for wild presence, observed in 2004/2005 and 2005/2006, in the Barra de Santa Angélica, in Alegre, Brazil. b) Number of individuals for wild presence, observed in 2004/2005 and 2005/2006, in the Barra de Santa Angélica, in Alegre, Brazil.

Tabela 1 - Diversidade florística artificializada na área de mata ciliar revegetada na Fazenda Barra de Santa Angélica. H’ = Índice de Shannon; J = Índice de Equabilidade de Pielou; № E = Número de espécies para a amostra; e № I = Número de indivíduos para a amostra.

Table 1 - Species diversity of the artificial regeneration in riparian forest in Santa Angélica, in Alegre, Brazil. $H^{\prime}$ = Shannon Index, $J=$ uniform index of Pielou, № $E=$ number of species and $N$ o $I=$ number of individuals.

\begin{tabular}{lcccc}
\hline \multicolumn{5}{c}{ Diversidade Florística Artificializada } \\
\hline Inventário & $\mathrm{H}^{\prime}$ & J & №E & №I \\
$2004 / 2005$ & $3,9348^{\text {a }}$ & 0,8681 & 93 & 800 \\
$2005 / 2006$ & $3,9550^{\text {a }}$ & 0,8665 & 96 & 798 \\
\hline
\end{tabular}

baixa densidade não estava previsto no projeto, sendo um evento associado à vontade do proprietário de plantar mudas de todas as espécies arbóreas que encontrasse.

\subsection{Dinâmica das estruturas horizontal, vertical e de classes de circunferência}

As análises da estrutura horizontal e do comportamento das espécies em relação ao crescimento, aqui expressas pelas estruturas dos inventários e taxas de dinâmica, permitem uma interpretação fitossociológica das mudanças da comunidade florestal implantada.
Em relação à estrutura horizontal artificializada, o povoamento apresentou densidade total de 665,83 e 665 indivíduos/ha, nos dois respectivos inventários, e dominância total de $6,63 \mathrm{~m}^{2} / \mathrm{h}$ e e 9,54 m²/ha. A Tabela 2 mostra que as espécies com maior Índice de Valor de Cobertura, respectivamente, foram: Joannesia princeps. (Pioneira), com 19,86 e 19,03; Anadenanthera colubrina (secundária inicial), com 17,75 e 17,06; Caesalpinia leyostachia (secundária inicial), com 16,71 e 14,90; Spondias macrocarpa (secundária tardia), com 11,30 e 13,16; Pterogyne nitens (secundária inicial), com 8,60 e 9,07\%; e Inga edulis (secundária inicial), com 5,85 e 6,53. Entre essas espécies se destaca Spondias macrocarpa (secundária tardia), que mesmo com menor número de indivíduos (19), em relação às outras, obteve dominâncias relativas crescentes, com aumento de 8,92 para 10,78 , o que indica potencial de ocupação no ambiente ripário estudado.

Quanto à estrutura vertical, as espécies com maior valor de posição sociológica relativa para os dois inventários, respectivamente, foram (Tabela 2): Caesalpinia leyostachia (secundária inicial), com 7,29 e 7,52\%; Anadenanthera colubrina (secundária inicial), com 7,27 e 6,89\%; Handroanthus serratifolius (secundária tardia), com 4,55 e 4,83\%; Pterogyne nitens (secundária inicial), com 4,46 e 4,48\%; Inga edulis (secundária inicial), com 4,73 e 4,45\%; e Handroanthus riodocensis

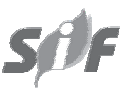

Revista Árvore, Viçosa-MG, v.34, n.5, p.835-851, 2010 
(secundária inicial), com 4,55 e 4,43\%. Destacam-se Anadenanthera colubrina e Pterogyne nitens, que apresentaram regularidade quanto à distribuição dos indivíduos pelos estratos. A estratificação vertical de uma floresta depende do regime de luz, grau de maturidade e estado de conservação do povoamento. Possui alta significância em análises ecológicas, por indicar as espécies que possuem maior facilidade em ocupar todos os estratos da floresta, bem como a adaptação delas quanto às condições ambientais estabelecidas no horizonte temporal (LAMPTRECHT, 1990).

Essas espécies são consideradas edificadoras de povoamentos em recuperação. Segundo Richards (1996), ao longo do perfil vertical da floresta ocorre decréscimo da disponibilidade de luz, no sentido da copa para o solo florestal, onde as espécies presentes no estrato superior recebem mais energia do que as dos estratos subsequentes. As espécies edificadoras em povoamentos de restauração possuem maior potencial na utilização da luz disponível, em consequência da ocupação dos distintos estratos verticais da floresta.

O crescimento das espécies, suas incorporações de biomassa e taxas de sobrevivência são excelentes indicadores da sustentabilidade de projetos de restauração de áreas degradadas. Segundo Nappo et al. (2005), a compreensão da dinâmica dos processos que ocorrem ao longo do tempo em florestas neotropicais em processo de recuperação é um grande desafio. Visualizar as mudanças, determinar suas principais causas e avaliá-las qualitativa e quantitativamente são o caminho para compreender os fenômenos que ocorrem na natureza.

Ao quantificar as espécies (Tabela2), descobriu-se que se destacam por apresentar elevados crescimentos brutos ( $\mathrm{m}^{2} / \mathrm{ha}$ ) Spondias macrocarpa, Joannesia princeps e Anadenanthera colubrina. O incremento periódico anual (mm/ano) indicou que as espécies com maiores respostas são: Spondias macrocarpa, Acacia mangium, Acacia auriculiformis, Joannesia princeps, Enterolobium contortisiliquum, Pterogyne nitens. Estes valores demonstram o potencial dessas espécies em se desenvolverem em áreas degradadas.

A Tabela 2 apresenta os dados taxonômicos das espécies e famílias botânicas, seus grupos ecológicos, síndromes de dispersão e presença silvestre. Os resultados dos cálculos das estruturas horizontal e vertical e a dinâmica, em termos de incremento periódico anual e crescimento bruto, estão apresentados por espécie nessa mesma tabela.

Tabela 2 - Relação das espécies arbóreas registradas no povoamento implantado em mata ciliar degradada, respectivos grupos ecológicos, parâmetros da estrutura horizontal, vertical e crescimento em diâmetro e área basal. Em que: GE = Grupo ecológico, $\mathrm{Pi}=$ Pioneira, $\mathrm{Si}=$ Secundária inicial, $\mathrm{St}=$ Secundária tardia, $\mathrm{Nc}$ = Não classificada; Dis $=$ Síndromes de dispersão, Ane $=$ Anemocórica, Zoo = Zoocórica e Aut = Autocórica; PS = Presença Silvestre, $\mathrm{Au}=$ Autóctone, $\mathrm{Al}=$ Alóctone; $\mathrm{N}$ = Número de indivíduos, $\mathrm{DR}=$ Densidade Relativa (\%), DoR = Dominância Relativa (\%), PSR = Posição Sociológica Relativa; VC = Valor de Cobertura; IPA = incremento periódico anual ( $\mathrm{mm} / \mathrm{ano})$; e CB = crescimento bruto (m2/ha).

Table 2 - List of species registred in artificial regeneration in riparian forest, their respective ecological group, parameters of the horizontal and vertical structures and growth in diameter and basal area. In that: GE= Ecological group, $\mathrm{Pi}=$ Pioneer, $\mathrm{Si}=$ Early secondary, $\mathrm{St}=$ Late secondary, $\mathrm{Nc}_{\mathrm{C}}=$ Unclassified; Dis = Dispersal syndromes, Ane: Anemochoric, Zoo: Zoochoric e Aut: Autochoric; $P S=$ Sylvan presence, Au = Autochthonus, Al= Alochthonus; $N=$ Number of individuals, $D R=$ Relative density (\%), DoR = Relative dominance (\%), PSR = Relative sociologic position and $V C=$ Coverage value; IPA = increase annual $(\mathrm{mm} /$ year $) ; C B=$ growth $(\mathrm{m} 2 / \mathrm{ha}) ; A B=$ basal area .

\begin{tabular}{|c|c|c|c|c|c|c|c|c|c|c|c|c|c|c|c|}
\hline \multirow{2}{*}{$\begin{array}{l}\text { Famílias e Respectivas } \\
\text { Espécies }\end{array}$} & \multirow[t]{2}{*}{ GE } & \multirow[t]{2}{*}{ SD } & \multirow[t]{2}{*}{ PS } & \multicolumn{5}{|c|}{$2004 / 2005$} & \multicolumn{5}{|c|}{$2005 / 2006$} & \multirow[t]{2}{*}{ IPA } & \multirow[t]{2}{*}{$\mathrm{CB}$} \\
\hline & & & & $\mathrm{N}$ & DR & DoR & VC & PSR & $\mathrm{N}$ & DR & DoR & VC & PSR & & \\
\hline $\begin{array}{l}\text { Achariaceae } \\
\text { Carpotroche brasiliensis Endl. }\end{array}$ & St & Aut & $\mathrm{Au}$ & 3 & 0,38 & 0,28 & 0,65 & 0,47 & 3 & 0,38 & 0,24 & 0,61 & 0,35 & 9,51 & 0,0043 \\
\hline $\begin{array}{l}\text { Anarcadiaceae } \\
\text { Anacardium occidentale L. }\end{array}$ & $\mathrm{Pi}$ & Zoo & $\mathrm{Al}$ & 6 & 0,75 & 0,22 & 0,97 & 0,66 & 5 & 0,63 & 0,16 & 0,79 & 0,53 & 0 & 0,0011 \\
\hline $\begin{array}{l}\text { Astronium fraxinifolium } \\
\text { Schott e Spreng. }\end{array}$ & St & Ane & $\mathrm{Au}$ & 4 & 0,5 & 0,2 & 0,7 & 0,49 & 4 & 0,5 & 0,22 & 0,72 & 0,51 & 16,86 & 0,0079 \\
\hline Schinnus terebinthifolius & $\mathrm{Pi}$ & Zoo & $\mathrm{Au}$ & 2 & 0,25 & 0,15 & 0,4 & 0,31 & 2 & 0,25 & 0,1 & 0,35 & 0,32 & 0 & 0,0000 \\
\hline
\end{tabular}

Radd. 
Tabela 2 - Cont.

Table 2 - Cont.

Spondias macrocarpa Engl.

Spondias purpurea L.

Annonaceae

Rollinia mucosa (Jacq.) Baill

Apocynaceae

Aspidosperma cylindrocarpon

M. Arg

Tabernaemontana hystrix

(Steud.) A.DC.

Araliaceae

$\begin{array}{llllllllllllllll}\text { Schefflera morototoni (Aubl.) } & \text { Si } & \text { Zoo } & \text { Au } & 5 & 0,63 & 0,11 & 0,73 & 0,37 & 4 & 0,5 & 0,13 & 0,63 & 0,37 & 6,63 & 0,006\end{array}$ Maguire, Steyerm. e Frodin

Bignoniaceae

Crescentia cujete L.

Handroanthus heptaphyllus

(Vell.) Mattos

Handroanthus riodocensis

(A.H.Gentry) S. Grose

Handroanthus serratifolius (Vahl) S. Grose

Jacaranda brasiliana

(Lam.) Pers

Jacaranda cuspidifolia

Mart.

Paratecoma peroba

(Rec.) Kuhlm.

Sparattosperma leucanthum

(Vell.) Schum.

Tabebuia roseo-alba

(Ridl.) Sand.

Zeyheria tuberculosa (Vell.)

Bur

Boraginaceae

Cordia superba Cham.

Cordia trichotoma (Vell.)

Arrab.

Cannabaceae

Trema micrantha (L.) Blum.

Caricaceae

Jacaratia heptaphylla

(Vell.) DC.

Chrysobalanaceae

Licania tomentosa (Benth.) Fritsch.

\section{Combretaceae}

Terminalia catappa L.

Terminalia kuhlmannii Law. e Sta.

\section{Dilleniaceae}

Dillenia indica B.

Euphorbiaceae

Croton floribundus Spreng.

Joannesia princeps Vell.

$\begin{array}{lllllllllllllll}\text { St } & \text { Zoo } & \text { Au } & 19 & 2,38 & 8,92 & 11,3 & 1,81 & 19 & 2,38 & 10,78 & 13,16 & 1 & 55,49 & 0,4371\end{array}$

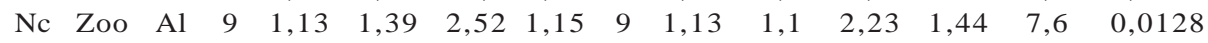

$\begin{array}{llllllllllllll}\text { St Zoo } & \mathrm{Au} & 2 & 0,25 & 0,02 & 0,27 & 0,31 & 2 & 0,25 & 0,03 & 0,28 & 0,19 & 3,98 & 0,0014\end{array}$

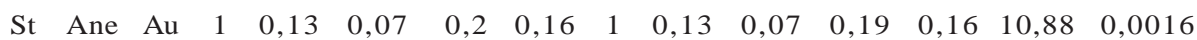

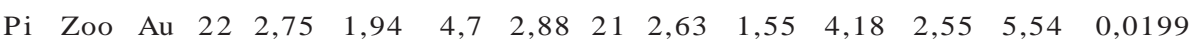

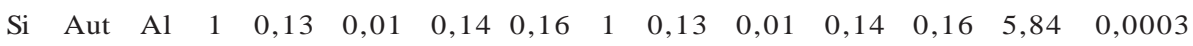

$\begin{array}{lllllllllllll}\text { St Ane } \mathrm{Au} & 4 & 0,5 & 0,14 & 0,64 & 0,62 & 4 & 0,5 & 0,13 & 0,63 & 0,64 & 6,83 & 0,0032\end{array}$

Si Ane Au $\begin{array}{llllllllllll}31 & 3,88 & 1,52 & 5,4 & 4,55 & 31 & 3,88 & 1,5 & 5,39 & 4,43 & 9,59 & 0,0426\end{array}$

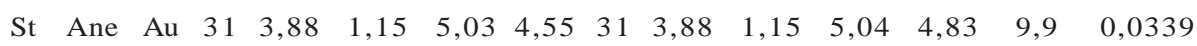

Si Ane Al $16 \quad 2 \quad \begin{array}{lllllllllll}1,28 & 3,28 & 2,35 & 16 & 2,01 & 1,46 & 3,46 & 2,3 & 14,38 & 0,0543\end{array}$

$\begin{array}{llllllllllllll}\mathrm{Pi} & \text { Ane Al } & 6 & 0,75 & 0,19 & 0,95 & 0,93 & 6 & 0,75 & 0,18 & 0,93 & 0,83 & 5,04 & 0,0041\end{array}$

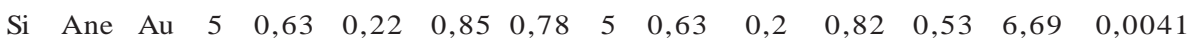

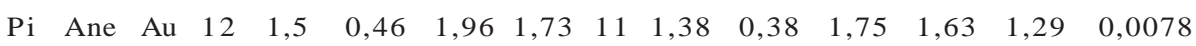

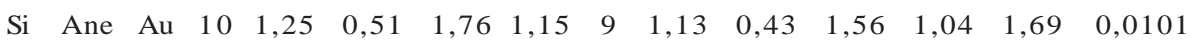

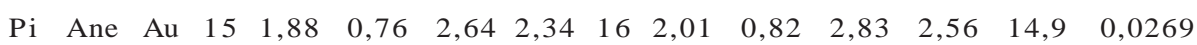

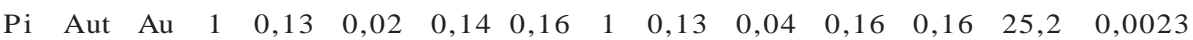

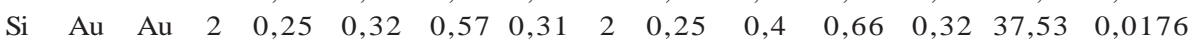

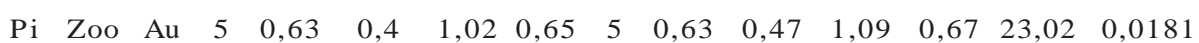

$\begin{array}{lllllllllllllll}\mathrm{Si} & \mathrm{Z} o o & \mathrm{Au} & 3 & 0,38 & 0,63 & 1,01 & 0,47 & 3 & 0,38 & 1,19 & 1,56 & 0,35 & 68,35 & 0,0714\end{array}$

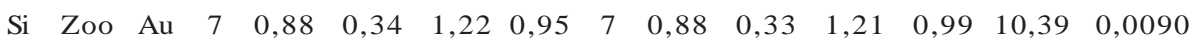

$\begin{array}{llllllllllllllll}\text { Nc } & \text { Zoo } & \mathrm{Al} & - & - & - & - & - & 1 & 0,13 & 0 & 0,13 & 0,03 & - & -\end{array}$

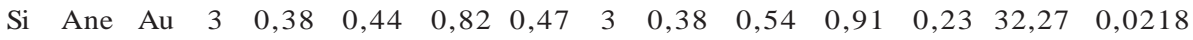

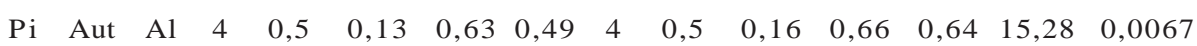

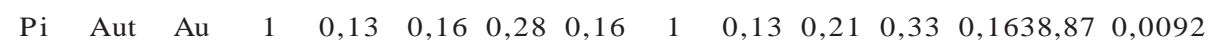

$\begin{array}{lllllllllll}\mathrm{Pi} \text { Zoo } & \mathrm{Au} & 43 & 5,38 & 14,4819,86 & 2,86 & 43 & 5,39 & 13,6419,03 & 2,9526,31 & 0,3417\end{array}$ 
Tabela 2 - Cont.

Table 2 - Cont.

\begin{tabular}{|c|c|c|c|c|c|c|c|c|c|c|c|c|c|c|}
\hline $\begin{array}{l}\text { Fabaceae-Caesalpinioideae } \\
\text { Apuleia leiocarpa Macbr. }\end{array}$ & $\mathrm{Si}$ & Ane & $\mathrm{Au}$ & 1 & 0,13 & 0,02 & 0,15 & 0,16 & 1 & 0,13 & 0,02 & 0,14 & $0,162,92$ & \\
\hline $\begin{array}{l}\text { Caesalpinia leyostachia } \\
\text { Benth. }\end{array}$ & $\mathrm{Si}$ & Aut & $\mathrm{Au}$ & 55 & 6,88 & 9,83 & 16,71 & 7,29 & 55 & 6,89 & 8,01 & 14,9 & $7,529,29$ & 0,113 \\
\hline $\begin{array}{l}\text { Delonix regia (Bojer ex } \\
\text { Hook.) Raf. }\end{array}$ & $\mathrm{Pi}$ & Aut & $\mathrm{Al}$ & 4 & 0,5 & 0,4 & 0,9 & 0,62 & 4 & 0,5 & 0,39 & 0,89 & $0,5113,79$ & 0,0103 \\
\hline $\begin{array}{l}\text { Hymenaea stigonocarpa } \\
\text { Mart. Ex Hayne }\end{array}$ & $\mathrm{Si}$ & Zoo & $\mathrm{Al}$ & 5 & 0,63 & 0,25 & 0,87 & 0,78 & 5 & 0,63 & 0,21 & 0,84 & $0,677,89$ & 0,0039 \\
\hline $\begin{array}{l}\text { Hymenaea stilbocarpa } \\
\text { (Hayne) Y.T. Lee e Langenh }\end{array}$ & St & Zoo & $\mathrm{Au}$ & 1 & 0,13 & 0 & 0,13 & 0,02 & 1 & 0,13 & 0,01 & 0,13 & $0,1612,73$ & 0,0005 \\
\hline Peltogyne angustifolia Duck. & St & Aut & $\mathrm{Au}$ & 4 & 0,5 & 0,14 & 0,64 & 0,49 & 4 & 0,5 & 0,12 & 0,62 & $0,514,11$ & 0,0016 \\
\hline $\begin{array}{l}\text { Peltophorum dubium } \\
\text { (Spreng.) Taub. }\end{array}$ & $\mathrm{Si}$ & Aut & $\mathrm{Au}$ & 15 & 1,88 & 2,04 & 3,92 & 1,95 & 15 & 1,88 & 2,07 & 3,95 & $1,7618,28$ & 0,0617 \\
\hline Pterogyne nitens Tul. & $\mathrm{Si}$ & Ane & $\mathrm{Au}$ & 32 & 4,01 & 4,6 & 8,6 & 4,46 & 32 & 4,01 & 5,06 & 9,07 & $4,4825,23$ & 0,1784 \\
\hline $\begin{array}{l}\text { Schizolobium parahyba } \\
\text { (Vell.) S. F. Blake }\end{array}$ & $\mathrm{Pi}$ & Ane & $\mathrm{Au}$ & 28 & 3,5 & 2,9 & 6,4 & 2,81 & 26 & 3,26 & 2,22 & 5,48 & $2,621,16$ & 0,0296 \\
\hline $\begin{array}{l}\text { Fabaceae-Cercideae } \\
\text { Bauhinia forficata Link }\end{array}$ & $\mathrm{Pi}$ & Aut & $\mathrm{Au}$ & 11 & 1,38 & 0,3 & 1,68 & 1,58 & 11 & 1,38 & 0,33 & 1,71 & $1,6310,93$ & 0,0118 \\
\hline Fabaceae-Faboideae & & & & & & & & & & & & & & \\
\hline Ateleia glazioveana Bail. & $\mathrm{Pi}$ & Ane & $\mathrm{Al}$ & 3 & 0,38 & 0,11 & 0,49 & 0,47 & 3 & 0,38 & 0,12 & 0,5 & $0,3512,38$ & 0,0043 \\
\hline Bowdichia virgilioides Kunth. & St & Aut & $\mathrm{Au}$ & 3 & 0,38 & 0,23 & 0,61 & 0,47 & 3 & 0,38 & 0,24 & 0,61 & $0,4813,77$ & 0,0072 \\
\hline $\begin{array}{l}\text { Centrolobium tomentosum } \\
\text { Guill. }\end{array}$ & $\mathrm{Si}$ & Ane & $\mathrm{Au}$ & 5 & 0,63 & 0,19 & 0,82 & 0,64 & 5 & 0,63 & 0,18 & 0,81 & $0,8 \quad 8,52$ & 0,0048 \\
\hline $\begin{array}{l}\text { Dalbergia nigra (Vell.) } \\
\text { Allemao ex Benth. }\end{array}$ & St & Ane & $\mathrm{Au}$ & 3 & 0,38 & 0,13 & 0,5 & 0,34 & 4 & 0,5 & 0,13 & 0,63 & $0,6414,13$ & 0,0037 \\
\hline alata Vog. & $\mathrm{Si}$ & Zoo & $\mathrm{Al}$ & 16 & 2 & 0,47 & 2,47 & 2,22 & 16 & 2,01 & 0,53 & 2,54 & $2,5612,41$ & 0,0197 \\
\hline $\begin{array}{l}\text { a indica Lam. } \\
\text { Hort. }\end{array}$ & $\mathrm{Pi}$ & Aut & $\mathrm{Al}$ & 5 & 0,63 & 0,3 & 0,92 & 0,51 & 5 & 0,63 & 0,3 & 0,93 & $0,6710,03$ & 0,0093 \\
\hline Erythrina mulungu Mart. & $\mathrm{Pi}$ & Aut & $\mathrm{Au}$ & 2 & 0,25 & 0,42 & 0,67 & 0,31 & 2 & 0,25 & 0,36 & 0,61 & $0,3211,71$ & 0,0058 \\
\hline Machaerium scleroxylon Tul. & St & Ane & $\mathrm{Au}$ & 1 & 0,13 & 0 & 0,13 & 0,02 & 1 & 0,13 & 0 & 0,13 & $0,037,69$ & 0,0002 \\
\hline Myroxylon peruiferum L. f. & St & Ane & $\mathrm{Au}$ & 5 & 0,63 & 0,23 & 0,85 & 0,78 & 5 & 0,63 & 0,28 & 0,91 & $0,817,34$ & 0,0117 \\
\hline $\begin{array}{l}\text { th.) Kunt. } \\
\text { oideae }\end{array}$ & $\mathrm{Pi}$ & Ane & $\mathrm{Al}$ & 2 & 0,25 & 0,21 & 0,46 & 0,17 & 3 & 0,38 & 0,37 & 0,75 & $0,2143,05$ & 0,0184 \\
\hline $\begin{array}{l}\text { Acacia auriculiformis A. } \\
\text { Cunn. }\end{array}$ & $\mathrm{Pi}$ & Zoo & $\mathrm{Al}$ & 12 & 1,5 & 4,4 & 5,9 & 1,35 & 11 & 1,38 & 4,53 & 5,91 & $1,2526,91$ & 0,1421 \\
\hline Acacia mangium Willd. & $\mathrm{Pi}$ & Zoo & $\mathrm{Al}$ & 7 & 0,88 & 4,25 & 5,13 & 0,58 & 6 & 0,75 & 4,59 & 5,34 & $0,5843,73$ & 0,1575 \\
\hline Albizia lebbeck (L.) Benth. & $\mathrm{Pi}$ & Aut & $\mathrm{Al}$ & 2 & 0,25 & 0,07 & 0,32 & 0,18 & 2 & 0,25 & 0,05 & 0,3 & $0,191,06$ & 0,0002 \\
\hline $\begin{array}{l}\text { Anadenanthera colubrina } \\
\text { (Vell.) Brenan }\end{array}$ & $\mathrm{Si}$ & Aut & $\mathrm{Au}$ & 60 & 7,51 & 10,24 & 417,75 & 7,27 & 60 & 7,52 & 9,64 & 17,16 & $6,8915,15$ & 0,2405 \\
\hline $\begin{array}{l}\text { Andira anthelmia (Vell.)J. } \\
\text { F. Macbr. }\end{array}$ & $\mathrm{Si}$ & Zoo & $\mathrm{Au}$ & 1 & 0,13 & 0,01 & 0,13 & 0,02 & 1 & 0,13 & 0,01 & 0,13 & $0,033,98$ & 0,0002 \\
\hline $\begin{array}{l}\text { Enterelobium contortisiliquum } \\
\text { (Vell.) Morong }\end{array}$ & Nc & Aut & $\mathrm{Au}$ & 23 & 2,88 & 3 & 5,88 & 3,17 & 23 & 2,88 & 3,43 & 6,32 & $3,2826,18$ & 0,129 \\
\hline Inga cylindrica (Vell.) Mart. & $\mathrm{Si}$ & Zoo & $\mathrm{Au}$ & 11 & 1,38 & 1,18 & 2,55 & 1,59 & 11 & 1,38 & 1,21 & 2,58 & $1,6317,6$ & 0,037 \\
\hline Inga edulis L. & $\mathrm{Si}$ & Zoo & $\mathrm{Au}$ & 33 & 4,13 & 1,72 & 5,85 & 4,73 & 32 & 4,01 & 2,52 & 6,53 & $4,4522,61$ & 0,1300 \\
\hline Mimosa caesalpinifolia Benth. & $\mathrm{Pi}$ & Aut & $\mathrm{Al}$ & 2 & 0,25 & 0,23 & 0,48 & 0,18 & 2 & 0,25 & 0,25 & 0,5 & $0,3220,31$ & 0,0087 \\
\hline Parkia nitida Miq. & $\mathrm{Pi}$ & Aut & $\mathrm{Al}$ & 1 & 0,13 & 0,51 & 0,64 & 0,16 & 1 & 0,13 & 0,57 & 0,7 & $0,1651,55$ & 0,0209 \\
\hline $\begin{array}{l}\text { Parkia pendula (Willd.) } \\
\text { Benth. }\end{array}$ & $\mathrm{Pi}$ & Aut & $\mathrm{Au}$ & 1 & 0,13 & 0,06 & 0,18 & 0,16 & 1 & 0,13 & 0,05 & 0,18 & $0,1611,41$ & 0,0015 \\
\hline $\begin{array}{l}\text { Piptadenia gonoacantha } \\
\text { (Mart.) J. F. Macbr. }\end{array}$ & $\mathrm{Pi}$ & Aut & $\mathrm{Au}$ & 4 & 0,5 & 1,13 & 1,63 & 0,24 & 4 & 0,5 & 0,92 & 1,42 & $0,6411,42$ & 0,0128 \\
\hline $\begin{array}{l}\text { Samanea tubulosa (Benth.) } \\
\text { Bar. e J.W. }\end{array}$ & $\mathrm{Pi}$ & Aut & $\mathrm{Al}$ & 3 & 0,38 & 0,81 & 1,18 & 0,21 & 3 & 0,38 & 0,69 & 1,06 & $0,2314,15$ & 0,012 \\
\hline
\end{tabular}


Tabela 2 - Cont.

Table 2 - Cont.

\begin{tabular}{|c|c|c|c|c|c|c|c|c|c|c|c|c|c|c|}
\hline $\begin{array}{l}\text { Lauraceae } \\
\text { Persea americana Mill. }\end{array}$ & Nc & Aut & $\mathrm{Al}$ & 1 & 0,13 & 0,02 & 0,15 & 0,16 & 1 & 0,13 & 0,02 & 0,14 & $0,163,25$ & 0,0003 \\
\hline $\begin{array}{l}\text { Lecythidaceae } \\
\text { Cariniana estrellensis (Raddi) } \\
\text { O.Kuntze }\end{array}$ & St & Ane & $\mathrm{Au}$ & 1 & 0,13 & 0 & 0,13 & 0,02 & 1 & 0,13 & 0,02 & 0,14 & $0,1624,14$ & 0,0013 \\
\hline $\begin{array}{l}\text { Lythraceae } \\
\text { Lafoensia glyptocarpa Koeh. } \\
\text { Malvaceae }\end{array}$ & $\mathrm{Pi}$ & Ane & $\mathrm{Au}$ & 2 & 0,25 & 0,09 & 0,34 & 0,31 & 2 & 0,25 & 0,09 & 0,34 & $0,3212,39$ & 0,002 \\
\hline $\begin{array}{l}\text { aziovii (Kuntze) } \\
\text { n. }\end{array}$ & $\mathrm{Si}$ & Ane & $\mathrm{Al}$ & 2 & 0,25 & 0,4 & 0,65 & 0,05 & 2 & 0,25 & 0,39 & 0,64 & $0,0621,75$ & 0,010 \\
\hline $\begin{array}{l}\text { Eriotheca gracilipes } \\
\text { (K.Schum.) A. Rob. }\end{array}$ & $\mathrm{Si}$ & Ane & $\mathrm{Au}$ & 1 & 0,13 & 0,04 & 0,17 & 0,16 & 1 & 0,13 & 0,05 & 0,17 & $0,1614,06$ & 0,0017 \\
\hline $\begin{array}{l}\text { Ochroma pyramidale } \\
\text { (Cav. Ex Lam.) Urb. }\end{array}$ & $\mathrm{Pi}$ & Ane & $\mathrm{Al}$ & 5 & 0,63 & 3,01 & 3,63 & 0,27 & 5 & 0,63 & 2,42 & 3,04 & $0,2916,23$ & 0,031 \\
\hline Pachira aquatica Aubl. & Nc & Aut & $\mathrm{Al}$ & 7 & 0,88 & 0,21 & 1,08 & 0,82 & 7 & 0,88 & 0,39 & 1,27 & $0,9930,15$ & 0,024 \\
\hline $\begin{array}{l}\text { bax grandiflorum } \\
\text { ob. }\end{array}$ & $\mathrm{Si}$ & Ane & $\mathrm{Au}$ & 10 & 1,25 & 1,23 & 2,48 & 0,77 & 10 & 1,25 & 1,05 & 2,31 & $1,0912,68$ & 0,0191 \\
\hline a brasiliensis Fr. All. & St & Ane & $\mathrm{Au}$ & - & - & - & - & - & 1 & 0,13 & 0,02 & 0,14 & $0,16-$ & - \\
\hline Sterculia elata Ducke & $\mathrm{Si}$ & Zoo & $\mathrm{Au}$ & 5 & 0,63 & 0,21 & 0,84 & 0,38 & 5 & 0,63 & 0,19 & 0,82 & $0,548,75$ & 0,004 \\
\hline Melia & & & & & & & & & & & & & & \\
\hline Tell. & St & Ane & $\mathrm{Au}$ & 1 & 0,13 & 0,13 & 0,25 & 0,16 & 1 & 0,13 & 0,09 & 0,22 & $0,162,65$ & 0,0005 \\
\hline (L.) Sleum. & $\mathrm{Si}$ & Zoo & $\mathrm{Au}$ & 13 & 1,63 & 0,15 & 1,78 & 1,89 & 12 & 1,5 & 0,16 & 1,67 & $1,794,41$ & 0,0078 \\
\hline Mel & $\mathrm{Si}$ & Zoo & $\mathrm{Al}$ & 5 & 0,63 & 0,25 & 0,87 & 0,78 & 5 & 0,63 & 0,32 & 0,95 & $0,6711,15$ & 0,0083 \\
\hline Kha & Nc & Aut & $\mathrm{Al}$ & 7 & 0,88 & 0,2 & 1,08 & 0,8 & 7 & 0 & 0,23 & 1,1 & $0,8516,36$ & 0,0142 \\
\hline Swietenia macrophylla King. & St & Ane & $\mathrm{Al}$ & 19 & 2,38 & 0,94 & 3,32 & 2,42 & 19 & 2,38 & 1,02 & 3,4 & $2,7814,74$ & 0,0355 \\
\hline & & & & & & & & & & & & & & \\
\hline am. & $\mathrm{Nc}$ & Zoo & $\mathrm{Al}$ & 1 & 0,13 &, 44 & 0,57 & 0,03 & 1 & 0,13 & 0,47 & 0,6 & $0,0342,29$ & 0,0158 \\
\hline géemelleira Kunth e & $\mathrm{Si}$ & Zoo & $\mathrm{Au}$ & 3 & 0,38 & 0,69 & 1,07 & 0,33 & 3 & 0,38 & 0,64 & 1,01 & $0,2218,11$ & 0,0149 \\
\hline & & & & & & & & & & & & & & \\
\hline olucrata DC. & $\mathrm{Pi}$ & Zoo & $\mathrm{Au}$ & 1 & 0,13 & 0 & 0,13 & 0,02 & 1 & 0,13 & 0,01 & 0,13 & $0,038,22$ & 0,0003 \\
\hline & $\begin{array}{l}\mathrm{Pi} \\
\mathrm{Pi}\end{array}$ & $\begin{array}{l}\text { Zoo } \\
\text { Zoo }\end{array}$ & $\begin{array}{l}\mathrm{Au} \\
\mathrm{Au}\end{array}$ & $\begin{array}{c}1 \\
19\end{array}$ & $\begin{array}{l}0,13 \\
2,38\end{array}$ & $\begin{array}{l}0,01 \\
0,98\end{array}$ & $\begin{array}{l}0,14 \\
3,36\end{array}$ & $\begin{array}{l}0,16 \\
2,14\end{array}$ & $\begin{array}{c}1 \\
19\end{array}$ & $\begin{array}{l}0,13 \\
2,38\end{array}$ & $\begin{array}{c}0,01 \\
0,8\end{array}$ & $\begin{array}{l}0,13 \\
3,18\end{array}$ & $\begin{array}{cc}0,03 & 0 \\
2,1 & 5\end{array}$ & $\begin{array}{l}0,0000 \\
0,0112\end{array}$ \\
\hline (L.) Skeels & $\mathrm{Pi}$ & Zoo & $\mathrm{Al}$ & 8 & 1 & 0,14 & 1,14 & 0,84 & 8 & 1 & 0,27 & 1,27 & $0,8821,98$ & 0,0162 \\
\hline ium malaccense (L.) & $\mathrm{Pi}$ & Zoo & $\mathrm{Al}$ & - & - & - & - & - & 1 & 0,13 & 0,01 & 0,14 & $0,03-$ & - \\
\hline $\begin{array}{l}\text { laccaceae } \\
\text { ia integrifolia } \\
\text { gel) Harms }\end{array}$ & $\mathrm{Pi}$ & Ane & $\mathrm{Au}$ & 9 & 1,13 & 0,3 & 1,43 & 1,26 & 12 & 1,5 & 0,48 & 1,98 & $1,3818,26$ & $0,024 \varepsilon$ \\
\hline dulcis Thumb. & $\mathrm{Pi}$ & Zoo & $\mathrm{Al}$ & 3 & 0,38 & 0,41 & 0,78 & 0,47 & 3 & 0,38 & 0,41 & 0,79 & $0,4820,16$ & 0,012 \\
\hline otria japonica Lindl. & St & Zoo & $\mathrm{Al}$ & 2 & 0,25 & 0,01 & 0,26 & 0,04 & 2 & 0,25 & 0,01 & 0,26 & $0,054,51$ & 0,000 \\
\hline $\begin{array}{l}\text { Rubiaceae } \\
\text { Anthocephalus indicus A. } \\
\text { Rich. }\end{array}$ & $\mathrm{Pi}$ & Aut & $\mathrm{Al}$ & 15 & 1,88 & 1,44 & 3,32 & 2,08 & 15 & 1,88 & 1,71 & 3,59 & $1,7622,45$ & 0,0681 \\
\hline Genipa americana L. & Nc & Aut & $\mathrm{Au}$ & 1 & 0,13 & 0,19 & 0,32 & 0,16 & 2 & 0,25 & 0,43 & 0,69 & $0,3264,41$ & 0,027 \\
\hline $\begin{array}{l}\text { Rutaceae } \\
\text { Citrus limon (L.) Burm. F. }\end{array}$ & $\mathrm{Pi}$ & Zoo & $\mathrm{Al}$ & 1 & 0,13 & 0,01 & 0,13 & 0,16 & 1 & 0,13 & 0,01 & 0,13 & $0,163,98$ & 0,0002 \\
\hline Casearia sylvestris Sw. & $\mathrm{Pi}$ & Zoo & $\mathrm{Au}$ & 3 & 0,38 & 0,06 & 0,44 & 0,47 & 3 & 0,38 & 0,05 & 0,43 & $0,354,57$ & 0,001 \\
\hline
\end{tabular}

Continua ... Continued... 
Tabela 2 - Cont.

Table 2 - Cont

\begin{tabular}{|c|c|c|c|c|c|c|c|c|c|c|c|c|c|c|}
\hline Sapindaceae & & & & & & & & & & & & & & \\
\hline Litchi chinensis Sonn. & Nc & Zoo & $\mathrm{Al}$ & 5 & 0,63 & 0,3 & 0,93 & 0,78 & 6 & 0,75 & 0,41 & 1,16 & $0,6920,32$ & 0,0184 \\
\hline Sapindus saponaria L. & CL & Aut & $\mathrm{Au}$ & 8 & 1 & 0,43 & 1,43 & 1,12 & 7 & 0,88 & 0,07 & 0,95 & $0,99 \quad 0$ & 0,0023 \\
\hline $\begin{array}{l}\text { Siparunaceae } \\
\text { Siparuna guianensis Aubl. }\end{array}$ & $\mathrm{Pi}$ & Zoo & $\mathrm{Au}$ & 1 & 0,13 & 0,01 & 0,13 & 0,16 & 1 & 0,13 & 0,01 & 0,13 & $0,166,63$ & 0,0003 \\
\hline $\begin{array}{l}\text { Urticaceae } \\
\text { Cecropia hololeuca Miq. }\end{array}$ & $\mathrm{Pi}$ & Zoo & $\mathrm{Au}$ & 5 & 0,63 & 0,87 & 1,49 & 0,65 & 5 & 0,63 & 0,73 & 1,36 & $0,6710,12$ & 0,0123 \\
\hline
\end{tabular}

A análise da dinâmica das populações das espécies com abundância $\geq$ a 10 indivíduos e para toda a comunidade do compartimento arbóreo (sem distinção de espécies) facilitou a compreensão do comportamento das espécies e está representada na Tabela 3. Sete espécies apresentaram mortalidade acompanhada de perda, a citar: Guarea guidonia, Acacia auriculiformis, Sparattosperma leucanthum, Schizolobium parahyba, Tabernaemontana hystrix, Handroanthus riodocensis e Inga edulis. Entre essas, a maioria apresentou taxa negativa de crescimento líquido em número de indivíduos, com exceção de Handroanthus riodocensis, que exibiu número de recrutas iguais ao de mortas e perda menor que o ganho em área basal.

As espécies Inga edulis, Acacia auriculiformis e Guarea guidonia registraram elevados ganhos e taxas de crescimento líquido em área basal. Isso é indicativo de adaptação ambiental das mesmas, enquanto a espécie Schizolobium parahyba apresentou a menor taxa de crescimento líquido em área basal, o que indica uma possível não adaptação ambiental, devido à morte de alguns indivíduos e crescimento limitado dos sobreviventes.

As espécies restantes não apresentaram taxas de rotatividade em número de indivíduos, apenas em área basal. As que se destacaram no registro de ganho e crescimento líquido, são, em ordem decrescente: Spondias macrocarpa, Anthocephalus indicus, Enterolobium contortisiliquum, Jacaranda brasiliana, Dpteryx alata, Bauhinea fortificata, Pterogyne nitens, Swietenia macrophylla, Zeyheria tuberculosa, Inga cylindrica, Peltophorum dubium, Handroanthus serratifolius, Joannesia princeps, Anadenanthera colubrina, Pseudobombax grandiflorum, Caesalpinia leyostachia e Psidium guajava.

Algumas espécies autóctones, como Enterelobium contortisiliquum, Inga edulis e Spondias macrocarpa, obtiveram crescimentos superiores ao da espécie alóctone Acacia auriculiformis, apesar do crescimento satisfatório da última, corroborando resultados de Ferreira et al. (2007), ao compararem o crescimento das espécies Acacia auriculiformis e Acacia mangium com algumas espécies autóctones. De acordo com Morais et al. (2005), plantios com arbóreas autóctones sugerem seu potencial para projetos contemporâneos, que objetivem o aumento de biodiversidade e o restabelecimento de serviços ambientais. A espécie Inga edulis, mesmo apresentando mortalidade, obteve plenas condições para o estabelecimento de sua população implantada, pois apresenta elevada capacidade de propagação vegetativa. Entre as espécies alóctones, Anthocephalus indicus obteve maior adaptação ao ambiente ripário degradado.

Quando a análise é realizada para toda a comunidade do compartimento arbóreo, a mortalidade e o recrutamento não apresentam diferenças significativas, apesar de a primeira ser de $1,57 \%{ }^{\text {ano-1 }}$ e a segunda, de $1,5 \%{ }^{\text {ano-1 }}$. Em contrapartida, o ganho em área basal supera, em grande significância, a perda, pois acrescentou $26,8 \%{ }^{\text {ano-1 }}$ enquanto perdeu $0,68 \%^{\text {ano-1 }}$. Dessa forma, as taxas de crescimento líquido foram de $-0,1 \%{ }^{\text {ano-1 }}$ para número de indivíduos e 34,6\% ${ }^{\text {ano-1 }}$ para área basal. Esse fenômeno entre a área basal e a densidade permite inferir que a comunidade se encontra em um processo de estruturação inicial, em que ocorre aumento expressivo da área basal e, devido à competição por grau de ocupação na área, supressão e morte de indivíduos menos adaptados ao local.

Na Tabela 3 são apresentados os resultados da dinâmica da estrutura horizontal artificializada para as populações de espécies com número de indivíduos $\geq 10$ e para toda a comunidade do compartimento arbóreo (sem distinção de espécies). 
Tabela 3 - Dinâmica quantitativa da estrutura horizontal artificializada. Em que: $\mathrm{M}=$ mortalidade (\%), $\mathrm{R}=$ recrutamento $\left(\%\right.$ ano $\left.^{-1}\right), \mathrm{P}=$ perda $(\%$ ano-1 $),\left[\mathrm{G}=\right.$ ganho $(\%$ ano-1) $] ; \mathrm{T}_{\mathrm{N}}=$ taxa de rotatividade em número de indivíduos $\left(\% \mathrm{ano}^{-1}\right), \mathrm{T}_{\mathrm{AB}}=$ taxa de rotatividade em área basal; $\mathrm{Ch}_{\mathrm{N}}=$ mudança líquida para número de indivíduos e $\mathrm{Ch}_{\mathrm{AB}}=$ mudança líquida para área basal $\left(\% \mathrm{ano}^{-1}\right)$.

Table 3 - Quantitative dynamics of the horizontal structure. In that: $M=$ mortality, $R=$ recruitment, $P=l o s s, G=$ win; $T_{N}=$ rotation tax in number of individuals, $T_{A B}=$ rotation tax in basal area, $C h_{N}=$ liquid change for number of individuals, $C h_{A B}=$ liquid change for basal area.

\begin{tabular}{|c|c|c|c|c|c|c|c|c|c|}
\hline \multirow[t]{2}{*}{ Espécies } & \multirow[t]{2}{*}{ GE } & \multicolumn{4}{|c|}{ Dinâmica } & \multicolumn{2}{|c|}{ Rotatividade } & \multicolumn{2}{|c|}{ Taxas } \\
\hline & & M & $\mathrm{R}$ & $\mathrm{P}$ & G & $\mathrm{Tn}$ & Tab & Chn & Chab \\
\hline Inga edulis & $\mathrm{Si}$ & 2,53 & 0,00 & 2,99 & 47,75 & 1,27 & 25,37 & $-2,53$ & 80,30 \\
\hline Spondias macrocarpa & St & 0,00 & 0,00 & 0,00 & 36,95 & 0,00 & 18,48 & 0,00 & 58,61 \\
\hline Anthocephalus indicus & $\mathrm{Pi}$ & 0,00 & 0,00 & 0,00 & 36,16 & 0,00 & 18,08 & 0,00 & 56,65 \\
\hline Enterelobium contortisiliquum & Nc & 0,00 & 0,00 & 0,00 & 34,08 & 0,00 & 17,04 & 0,00 & 51,70 \\
\hline Jacaranda brasiliana & $\mathrm{Si}$ & 0,00 & 0,00 & 0,00 & 33,76 & 0,00 & 16,88 & 0,00 & 50,96 \\
\hline Dipteryx alata & $\mathrm{Si}$ & 0,00 & 0,00 & 0,00 & 33,46 & 0,00 & 16,73 & 0,00 & 50,28 \\
\hline Bauhinia forficata & $\mathrm{Pi}$ & 0,00 & 0,00 & 0,00 & 32,10 & 0,00 & 16,05 & 0,00 & 47,28 \\
\hline Pterogyne nitens & $\mathrm{Si}$ & 0,00 & 0,00 & 0,00 & 31,89 & 0,00 & 15,94 & 0,00 & 46,81 \\
\hline Swietenia macrophylla & St & 0,00 & 0,00 & 0,00 & 31,33 & 0,00 & 15,66 & 0,00 & 45,62 \\
\hline Zeyheria tuberculosa & $\mathrm{Pi}$ & 0,00 & 0,00 & 0,00 & 31,22 & 0,00 & 15,61 & 5,53 & 44,75 \\
\hline Acacia auriculiformis & $\mathrm{Pi}$ & 6,99 & 0,00 & 0,32 & 28,24 & 3,50 & 14,28 & $-6,99$ & 38,46 \\
\hline Inga cylindrica & $\mathrm{Si}$ & 0,00 & 0,00 & 0,00 & 27,66 & 0,00 & 13,83 & 0,00 & 38,24 \\
\hline Peltophorum dubium & $\mathrm{Si}$ & 0,00 & 0,00 & 0,00 & 26,84 & 0,00 & 13,42 & 0,00 & 36,69 \\
\hline Handroanthus serratifolius & St & 0,00 & 0,00 & 0,00 & 26,42 & 0,00 & 13,21 & 0,00 & 35,90 \\
\hline Handroanthus riodocensis & $\mathrm{Si}$ & 2,70 & 2,70 & 2,42 & 28,91 & 2,70 & 15,67 & 0,00 & 32,96 \\
\hline Joannesia princeps & $\mathrm{Pi}$ & 0,00 & 0,00 & 0,00 & 22,42 & 0,00 & 11,21 & 0,00 & 28,89 \\
\hline Anadenanthera colubrina & $\mathrm{Si}$ & 0,00 & 0,00 & 0,00 & 22,33 & 0,00 & 11,16 & 0,00 & 28,75 \\
\hline Pseudobombax grandiflorum & $\mathrm{Si}$ & 0,00 & 0,00 & 0,00 & 16,11 & 0,00 & 8,05 & 0,00 & 19,20 \\
\hline Guarea guidonia & $\mathrm{Si}$ & 13,00 & 6,99 & 23,47 & 48,06 & 9,99 & 35,77 & $-6,45$ & 17,84 \\
\hline Caesalpinia leyostachia & $\mathrm{Si}$ & 0,00 & 0,00 & 0,00 & 12,48 & 0,00 & 6,24 & 0,00 & 14,25 \\
\hline Psidium guajava & $\mathrm{Si}$ & 0,00 & 0,00 & 0,00 & 12,38 & 0,00 & 6,19 & 0,00 & 14,13 \\
\hline Tabernaemontana hystrix & $\mathrm{Pi}$ & 3,80 & 0,00 & 0,45 & 11,33 & 1,90 & 5,89 & $-3,80$ & 11,77 \\
\hline Sparattosperma leucanthum & $\mathrm{Pi}$ & 6,99 & 0,00 & 6,30 & 18,58 & 3,50 & 12,44 & $-6,99$ & 8,35 \\
\hline Schizolobium parahyba & $\mathrm{Pi}$ & 5,99 & 0,00 & 4,30 & 11,78 & 2,99 & 8,04 & $-5,99$ & 4,04 \\
\hline Comunidade arbórea & Nc & 1,57 & 1,5 & 0,68 & 26,8 & 1,5 & 13,7 & $-0,1$ & 34,6 \\
\hline
\end{tabular}

O comportamento da distribuição do número de indivíduos, por classe de circunferência da comunidade arbórea estudada, nos dois inventários (2004/2005 e 2005/2006), apresenta a curva em forma de um “J” reverso, conforme descrito por DeLiocourt (1898), e, segundo Janzen (1980), é característica de Florestas Naturais (Figura 3). Entre os dois inventários, apenas nas classes de 5-17 cm e de 17-29 cm é que o número de indivíduos é maior no primeiro levantamento, enquanto em todas as outras classes de circunferência o segundo inventário realizado aparece com maior número de indivíduos, culminando com o aparecimento, apenas na segunda medição, de indivíduos nas classes de circunferência de $125-137$ cm e de $137-149$ cm, o que demonstra o crescimento em área basal dos indivíduos. Pelo teste de Kolmogorov-Smirnov, verificaram-se diferenças significativas nas distribuições de CAP, quando foram comparados os períodos de 2004/2005 com 2005/2006 ( $\chi$ = 19,5795; $\mathrm{P}<0,0001)$. As diferenças entre as distribuições de frequência de CAP ocorreram devido à mortalidade concentrada em indivíduos menores, mais suscetíveis às mudanças dos indivíduos sobreviventes das classes de circunferência superiores e à ausência de recrutas.

A comunidade florestal implantada se estrutura em semelhança a um processo natural, exceto pela não reposição de indivíduos jovens em função da insipiente regeneração natural. Esse fato pode ser explicado, em parte, pelo fato de que a grande maioria dos indivíduos plantados ainda não entrou em fase reprodutiva, não atuando, assim, como promotores diretos da regeneração natural. 


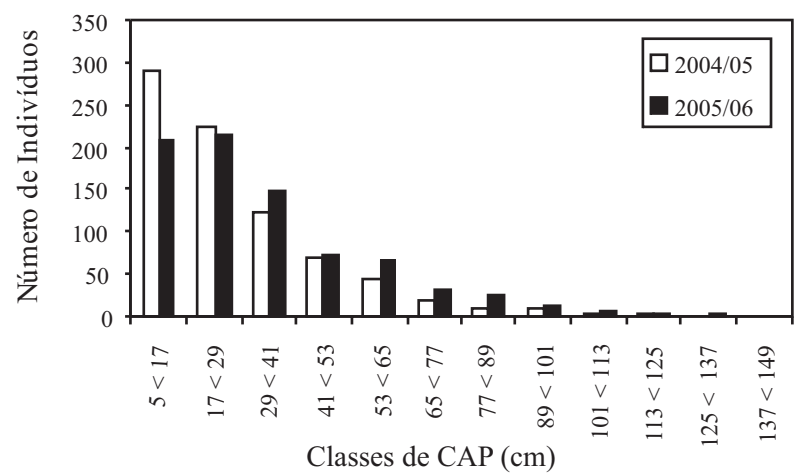

Figura 3 - Número de indivíduos do povoamento implantado, por classe de circunferência, observado em 2004/ 2005 e 2005/2006, na Fazenda Barra de Santa Angélica, em Alegre, ES.

Figure 3-Number of individuals of the artificial regeneration, for circumference class, observed in 2004/2005 and 2005/2006, in the Barra de Santa Angélica, in Alegre, Brazil.

\section{CONCLUSÕES}

De acordo com os resultados obtidos nesse estudo, conclui-se que a composição florística, a estrutura e a diversidade não diferiram entre os períodos de monitoramento.

A estratificação em classes de altura foi à semelhança de povoamentos heterogêneos naturais e as espécies edificadoras do povoamento, também se destacaram na estrutura horizontal artificializada, e em termos de crescimento bruto e incremento periódico anual.

As espécies utilizadas como edificadoras da revegetação da área de floresta ciliar estudada foram: Anadenanthera colubrina, Caesalpinia leyostachia, Acacia auriculiformis, Acacia mangium, Handroanthus serratifolius, Inga edulis, Joannesia princeps, Pterogyne nitens, Enterelobium contortisiliquum, Tabernaemontana hystrix e Anthocephalus indicus.

A distribuição de circunferências da comunidade implantada ocorre em forma de "J" reverso, havendo a predominância de indivíduos pioneiros em todas as classes de CAP.

A dinâmica da estrutura horizontal apontou que, para o sucesso, continuidade e desenvolvimento da recuperação da área, seja monitorada a regeneração natural em relação a sua presença e eficiência dos fatores bióticos e abióticos que nela interferem.
O baixo desenvolvimento da regeneração natural, ainda não atingindo a classe de inclusão de CAP desse estudo, reflete uma vulnerabilidade do sistema em relação a sua sustentabilidade.

\section{REFERÊNCIAS BIBLIOGRÁFICAS}

APG II. Na update of the Angiosperm Phylogeny Group classification for the orders and families of flowering plants: APG II. Botanical Journal of the Linnaean Society, v. 141, p. 399 -436, 2003.

AZEVEDO, C. P.; SOUZA, A. L.; JESUS, R. M. Um modelo de matriz de transição para prognose do crescimento de um povoamento natural remanescente não manejado de mata atlântica. Revista Árvore, v. 19, n. 2, p. 187-199, 1995.

BECHARA, F. C.; CAMPOS FILHO, E. M.; BARRETTO, K. D.; GABRIEL, V. A.; ANTUNES, A. Z.; REIS, A. Unidades Demonstrativas de Restauração Ecológica através de Técnicas Nucleadoras de Biodiversidade. Revista Brasileira de Biociências, Porto Alegre, v. 5, supl. 1, p. 9-11, jul. 2007. (Nota científica).

BRASIL. Ministério do Interior. Manual de recuperação de áreas degradadas pela mineração: Técnica de Revegetação. IBAMA. Brasília, DF, 1990. 96P.

BUDOWSKI, G. Distribution of tropical American rain forest species in the light of successional process. Turrialba, 15:40-42. 1965.

CARVALHO, P. E. R., Espécies florestais brasileiras: recomendações

silviculturais, potencialidades e uso da madeira. Empresa Brasileira de Pesquisa Agropecuária, Centro Nacional de Pesquisa de Florestas. - Colombo: EMBRAPA - CNPF; Brasília-DF, 1994. 640p.

DeLIOCOURt, F. 1898. De l'amenagement des Sapinieres. Bulletin De la Societe Forestiere de Franch-Conte et Belfort.

DENSLOW, J.S. Gap partitioning among tropical rain forest trees. Biotropica (Suppl.), 12; 4755. 1980. 
DURIGAN, G. Métodos para análise de vegetação arbórea. In: Cullen-Júnior, L.; Rudran, R.; Valladares-Padua, C. (Orgs.). Métodos de estudos em biologia da conservação e manejo da vida silvestre. UFPR, Curitiba, Paraná, p. 455-479, 2003.

ENGEL, V.L.; PARROTTA, J.A. Definindo a restauração ecológica: tendências e perspectivas mundiais. In: Kageyama, P.Y.; Oliveira, R.E.; Moraes, L.F.D.; Engel, V.L.; Gandara, F.B. (eds.) Restauração Ecológica de Ecossistemas Naturais. FEPAF, Botucatu. 2003. 340p.

FERREIRA, R. L. C. Estrutura e dinâmica de uma floresta secundária de transição, Rio Vermelho e Serra Azul de Minas, MG. Viçosa, MG: UFV, 1997. 208 p. Tese (Doutorado em Ciência Florestal) Universidade Federal de Viçosa, 1997.

FERREIRA, W. C.; BOTELHO, S. A. ; DAVIDE, A. C. ; FARIA, J. M. R. . Avaliação do crescimento do estrato arbóreo de área degradada revegetada à margem do Rio Grande, na Usina Hidrelétrica de Camargos, MG.

Revista Árvore, v. 37, p. 177-185, 2007.

GANDOLFI, S.; LEITÂO-FILHO, H. F.; BEZERRA, C. L. E. Levantamento florístico e caráter sucessional das espécies arbustivo-arbóreas de uma floresta mesófila semidecídua no município de Guarulhos, SP. Revista Brasileira de Biologia, Rio de janeiro, v. 55, n. 4, p. 753-767, 1995.

GANDOLFI, S. História Natural de uma Floresta Estacional Semidecidual no município de Campinas (São Paulo, Brasil). 2000. 520f. Tese (Doutorado em Biologia Vegetal) - Universidade Estadual de Campinas, Campinas, 2000.

GOODLAND, R. Glossário de ecologia brasileira. Manaus: Instituto Nacional de Pesquisa da Amazônia, 1975.

HUSCH, B.; MILLER, C. I.; BEERS, T. W. Forest mensuration. Malabar: Krieger, 1993. 402p.

VELOSO, H. P., RANGEL FILHO, A. L. R.; LIMA, J. C. A. Classificação da vegetação brasileira, adaptada a um sistema universal. Rio de Janeiro: IBGE, 1991.
INCAPER. Sistemas de informações agrometeorológicas. Disponível em: <http:// www.incaper.es.gov.br/clima/alegre_bol.htm>. Acesso em: 21 ago. 2006.

JANZEN, D.H. Ecologia vegetal nos trópicos. São Paulo: EDUSP, 1980. 79p.

JESUS, R. M. Restauração de um fragmento na mata atlântica: uma avaliação no $1 I^{\circ}$ ano. In: V Simpósio Nacional de Recuperação de Áreas Degradadas, 2002, Belo Horizonte-MG. V SINRAD- Palestras. Lavras : Editora UFLA, 2002. v. 1. p. 146-168.

KAGEYAMA, P.Y.; FREIXÊDAS, V.M.; GERES, W.L.A.; DIAS, J.H.P e BORGES, A.S. Consórcio de espécies nativas de diferentes grupos sucessionais em Teodoro Sampaio-SP. In: II Congresso Nacional sobre Essências Nativas, São Paulo, SP, Inst. Flor. São Paulo, p. 527-533. 1992.

KORNING, J. e BALSLEV, H. Growth and mortality of trees in Amazonian tropical rain forest in Ecuador. Journal of Vegetation Science. v. 4, n.1, p. 77-86, 1994.

\section{LAMPRECHT, H.; Silvicultura nos}

trópicos: Ecossistemas florestais e respectivas espécies arbóreas possibilidades e métodos de aproveitamento sustentado. Instituto de Silvicultura da Universidade Gottingen. Eschborn. Rep. Federal da Alemanha. 1990. 343p.

LEITÃO FILHO, H. F. Considerações sobre a florística de florestas tropicais e sub-tropicais do Brasil. IPEF, n.35, p.41-46, 1987.

LEMAIRE, F. C. e LEMAIRE, E.

Dictionnaire de l'environnement. Verviers, Marabout, 1975.

LORENZI, H. Árvores Brasileiras: Manual de Identificação e Cultivo de Plantas Arbóreas do Brasil, Vol. 1. 3.ed. Nova Odessa, SP: Instituto Plantarum, 2000.

LORENZI, H. Árvores Brasileiras: Manual de Identificação e Cultivo de Plantas Arbóreas do Brasil, Vol.2. 2.ed. Nova Odessa, SP: Instituto Plantarum, 2002.

Revista Árvore, Viçosa-MG, v.34, n.5, p.835-851, 2010 
LORENZI, H. Árvores Exóticas no Brasil: madereiras, ornamentais e aromáticas. Nova Odessa, SP: Instituto Plantarum, 2003.

LORENZO, J. S. Regeneração natural de uma área minerada de bauxita em Poços de Caldas, Minas Gerais. ViçosaMG, UFV: 1991. 151 p. Tese (Mestrado em Ciência Florestal) - Universidade Federal de Viçosa, 1991.

MAGURRAN, A. E. Ecological diversity and its measurement. New Jersey: Princeton University, 1988. 179 p.

MAJER, J. D. Animals in primary sucession: the role of fauna in reclaimed lands. Cambridge University Press, Cambridge, U. K. 1989

MARGALEF, R., Ecologia. Barcelona, 1989. 951 p.

MARTÍNEZ-RAMOS, M. Claros, ciclos vitales de los árboles tropicales y regeneración natural de las selvas altas perenifolias. In: Gómez-Pompa, A.; Del Amo, S. Investigaciones sobre la regeneración de selvas altas en Veracruz. México, vol.2, pp. 191-239, 1985.

MARTINS, F. R. Estrutura de uma floresta mesófila. Campinas: Ed. Da UNICAMP, 1993. 246 p.

MARTINS, S. V.; RODRIGUES, R. R. Gap-phase regeneration in a semideciduous mesophytic forest, south-eastern Brazil. Plant Ecology, Holanda, v. 163, n. 1, p. 51-62, 2002.

MACHADO E., L., M. Heterogeneidade espacial e temporal em um fragmento de floresta estacional em Lavras, MG. Lavras-MG, UFLA: 2005. 101 p. Dissertação (Mestrado em Manejo Ambiental) - Universidade Federal de Lavras, 2005.

MORAES, L. F. D. ; ASSUMPÇÃO, J. M. ; LUCHIARI, C. ; PEREIRA, T. S. . Plantio de espécies arbóreas nativas para a restauração ecológica na Reserva Biológica de Poço das Antas, Rio de Janeiro, Brasil. Rodriguesia, v. 57, p. 477-489, 2006.

MUELLER-DOMBOIS, D. e ELLENBERG, H.A. Aims and methods of vegetation ecology. New York, J. Wiley, 1974. 547p.
NAPPO, M. E.; GRIFFITH, J, J.; MARTINS, S. V.; DE MARCO JÚNIOR, P.; SOUZA, A. L.; OLIVEIRA-FILHO A. T.. Dinâmica da estrutura fitossociológica da regeneração natural de espécies arbóreas e arbustivas no sub-bosque de povoamento puro de Mimosa scabrella Bentham, em área minerada, em Poços de Caldas-MG.

Revista Árvore. Viçosa - MG, v. 28, no 6, p. 811-829, 2004.

NAPPO, M. E.; GRIFFITH, J, J.; MARTINS, S. V.; DE MARCO JÚNIOR, P.; SOUZA, A. L.; OLIVEIRA-FILHO A. T.. Dinâmica da estrutura diamétrica da regeneração natural de espécies arbóreas e arbustivas no sub-bosque de povoamento puro de Mimosa scabrella Bentham, em área minerada, em Poços de Caldas-MG.

Revista Árvore. Viçosa - MG, v. 29, no 1, p. 35-46, 2005. [

NASCIMENTO, M.C. do; SOARES, V.P.; RIBEIRO, C.A.A.S; SILVA, E. Uso do geoprocessamento na identificação de conflito de uso da terra em áreas de preservação permanente na bacia hidrográfica do Rio Alegre, Espírito Santo. Ciência Florestal, Santa Maria, v. 15, n. 2, p. 207-220. 2005.

NOFFS, P. da S; GALLI, L. F; GONÇALVES, J. C. Recuperação de áreas degradadas da Mata Atlântica: uma experiência da CESP, São Paulo, 2 ed., n. 03, 2000, 48p.

OLIVEIRA-FILHO, A. T. Estudos ecológicos da vegetação como subsídios para programas de revegetação com espécies nativas: uma proposta metodológica. Cerne, v. 1, n. 1, p. 64-72, 1994.

OLIVEIRA-FILHO, A. T.; MELLO, J. M.; SCOLFORO, J. R. S. Effects of past disturbance and edges on tree community struture and dynamics within a fragment of tropical semidecidous Forest in South-eastern Brazil over a five-year period (1987-1992). Plant Ecology, v.131, n.1, p. 45-66, 1997.

OLIVEIRA FILHO, A., T.; RATTER, J. A. Padrões Florísticos das Matas Ciliares da Região do Cerrado e a Evolução das Paisagens do Brasil Central durante o Quartenário Tardio. In: RODRIGUES, R. R.; LEITÃO FILHO, H. de F. Matas ciliares: conservação e recuperação. São Paulo: Universidade de São Paulo, 2000. p. 73-89. 
PEREIRA, I., M. Estudo da vegetação remanescente como subsídio à recomposição de áreas alteradas nas cabeceiras do rio Grande, Minas Gerais. Doutorado em Engenharia Florestal. Lavras-MG, UFLA: 2006. 261 p. Tese (Doutorado em Manejo Ambiental) - Universidade Federal de Lavras, 2006.

PEZZOPANE, J. E. M.; SANTOS, E. A. ; SANTOS, A. R. dos; SILVA, G. F. das ; REIS, E. F. dos. Delimitação de zonas agroclimaticas no estado do Espirito Santo. Revista Brasileira de Agrometeorologia, Piracicaba, v. 14, n. 2, p. 149-156, 2006.

PIELOU, E.C. An introduction to mathematical ecology. New York: J. Wiley, 1969. 286p.

POOLE, R. W. An introduction to quantitative ecology. New York: McGrawHill, 1974. 532p.

REIS A.; BECHARA, F. C.; ESPÍNDOLA M. B. de e VIEIRA, N. K. Restauração de Áreas Degradadas: A Nucleação como Base para os Processos Sucessionais. Revista Natureza e Conservação, v. 1, n. 1, p. 85-92, 2003.

RICHARDS, P. W. The tropical rain forest an ecological study. Second edition, Cambridge University Press, 1996.

RIZZINI, C. T. Tratado de Fitogeografia do Brasil. São Paulo, SP: Ed.USP, 1979.

RODRIGUES, R., R.; NAVE, A. G. Heterogeneidade Florística da Matas Ciliares. In: RODRIGUES, R. R.; LEITÃO FILHO, H. de F. Matas ciliares: conservação e recuperação. São Paulo: Universidade de São Paulo, 2000. p. 45-71.
RODRIGUES, R., R. Uma Discussão Nomenclatural das Formações Ciliares. In: RODRIGUES, R. R.; LEITÃO FILHO, H. de F. Matas ciliares: conservação e recuperação. São Paulo: Universidade de São Paulo, 2000. p. 91-100.

ROLIM, S. G., COUTO, H. T. Z., JESUS, R. M. Mortalidade e recrutamento de árvores na floresta atlântica em Linhares (ES). Scientia Forestalis (IPEF), v.55, p. 49-69, 1999.

SCOLFORO, J.R.S. MELLO, J.M. Inventário florestal. Lavras: UFLA/FAEPE, 1997. 344p.

SHEIL, D., BURSLEM, D. F. R. P. e ALDER, D. The interpretation and misinterpretation of mortality rate measures. Journal of Ecology, v. 83, n. 2, p. 331-333. 1995.

SHEIL, D., JENINGS, S. e SAVILL, P. Long-term permanent plot observations of dynamics in Budongo, a Ugandan rain forest. Journal of Tropical Ecology, v. 16, n.1, p. 765-800. 2000.

SOUZA, A. L. Estrutura, dinâmica e manejo de florestas tropicais. Viçosa: UFV, 1999. 122 p. (Notas de Aula).

SWAINE, M. D. e WHITMORE, T. C. 1988. On the definition of ecological species groups in tropical rain forest. Vegetation, The Hague, v.75, n.2, p.81-86.

VAN DER PIJL, L. Principles of dispersal in higher plants. 3rd ed. Springer-Verlarg, Berlin. 1982.

WERNECK, M. S.; FRANCESCHINELLI, E. V. Dynamics of a dry forest fragment after the exclusion of human disturbance in southeastern Brazil. Plant Ecology. v. 174, n. 2, p. 337-346, 2004.

ZAR, J. H. Biostatistical analysis. 4. ed. Englewood Cliffs: Prentice Hall, 1999. 